\title{
DO BITCOIN AO "RENMIMBI DIGITAL": SOBERANIA MONETÁRIA, SEGURANÇA FINANCEIRA E A POSSÍVEL ORDEM FINANCEIRA CENTRADA NA CHINA
}

Resumo: O bitcoin foi lançado em 2009 com a pretensão de ser moeda privada, não institucional e livre dos arbítrios governamentais. Não teve êxito como tal, mas mostrou-se um meio para transferir direitos fora da vigilância e do controle das autoridades nacionais e internacionais. Por isso, o governo da China, extremamente cioso da sua soberania monetária, o considerou uma ameaça à segurança financeira, reprimindo o seu uso. Apesar disso, identificou nas tecnologias do bitcoin uma oportunidade para criar uma moeda digital governamental. O resultado foi a instituição do "renmimbi digital", com o qual pretende maior rapidez e eficácia na execução das políticas internas, controlar essa nova modalidade de transações comerciais e, se possível, erguer as bases de uma nova ordem financeira centrada na China.

Palavras-chave: China. Renmimbi digital (e-RMB). Bitcoin. Soberania monetária. Segurança financeira.

\section{FROM BITCOIN TO "DIGITAL RENMIMBI": MONETARY SOVEREIGNTY, FINANCIAL SECURITY AND CHINA'S LIKELY NEW FINANCIAL ORDER}

\begin{abstract}
Bitcoin was launched in 2009 with the aim of being a private, noninstitutional, free from government discretion currency. It has never been successful as such, but it has proved to be a means to transfer rights outside the surveillance and control of national and international authorities. Therefore, the Chinese government, extremely conscientious of its monetary sovereignty, considered bitcoin a threat to national financial security, repressing its use. Nevertheless, it identified in bitcoin's technologies an opportunity to create a government digital currency. The outcome was the institution of the "digital renmimbi" (e-RMB), with which it intends to increase the speed and efficiency in the execution of internal policies, to control this new modality of commercial transactions and, if feasible, to erect the bases of a new China-centered financial order.
\end{abstract}

Keywords: China. Digital renmimbi (e-RMB). Bitcoin. Monetary sovereignty. Financial security.

\section{DEL BITCOIN AL "RENMIMBI DIGITAL": SOBERANIA MONETARIA, SEGURIDAD FINANCIERA Y EL POSIBLE NUEVO ORDEN FINANCIERO DE CHINA}

Resumen: El bitcoin fue lanzado en 2009 con la pretensión de ser una moneda privada, no instuticional y libre de discreción del gobierno. No tuvo éxito como tal, pero resultó ser un medio para transferir derechos fuera de la vigilancia y el control de las autoridades nacionales e internacionales. Por esta razón, el gobierno chino,

\footnotetext{
1 Universidade Federal do Rio de Janeiro (UFRJ), Rio de Janeiro, Brasil, danskos@gmail.com, https://orcid.org/0000-0002-3010-6004

${ }^{2}$ Universidade Federal do Rio de Janeiro (UFRJ), Universidade do Estado do Rio de Janeiro (Uerj), Rio de Janeiro, Brasil, valterduarteff@yahoo.com.br, https://orcid.org/0000-0001-9196-0151
} 
extremadamente pendiente de su soberanía monetaria, lo consideró una amenaza para la seguridad financiera, reprimiendo su uso. A pesar de esto, identificó en las tecnologías de bitcoin una oportunidad para crear una moneda digital gubernamental. El resultado fue la institución del "renmimbi digital", con el que pretende aumentar la velocidad y eficiencia en la ejecución de políticas internas, controlar la nueva modalidad de transacciones comerciales y, se posible, sentar las bases para un nuevo orden financiero centrada en China.

Palabras clave: China. Renmimbi digital (e-RMB). Bitcoin. Soberanía monetária. Seguridad financiera.

\section{Prólogo}

Apesar de poderem coincidir, neste trabalho não se considera que moeda e dinheiro sejam a mesma coisa. Moeda será qualquer objeto utilizado para transferir direitos de apropriação de bens. Porém, dinheiro, além de possuir esse atributo, será objeto de representação de comando governamental. De modo que todo dinheiro será considerado moeda e nem toda moeda será considerada dinheiro, exceção feita às moedas governamentais que são, em rigor, dinheiro.

\section{Introdução}

Lançado em 2009, o bitcoin foi criado para ser moeda privada, descentralizada, não institucional, transfronteiriça, politicamente "neutra" e de utilidade universal. Seria um instrumento pioneiro de liberdade e empoderamento individual frente às instituições estabelecidas, destinado a servir como pedra fundamental de um "livre mercado" de escala global à margem dos arbítrios governamentais.

No entanto, essa ambição não se mostra viável, como se vê à luz de qualquer análise rigorosa dos fatos. De saída, não é possível considerar que o bitcoin seja dinheiro. Longe disso, pois Ihe faltam diversas propriedades definidoras desse principal meio executivo governamental, a começar pela autoridade que o institua, garanta a sua validade e o faça circular nos seus limites de legitimidade política.

Destaque-se que o bitcoin não tem também qualquer dos atributos distintivos do dinheiro, dentre eles, o mais importante quando se trata de capitalismo, que é o de poder fazer o seu preço em si mesmo: a taxa de juros. Por sinal, com preço extremamente instável e definido em moedas governamentais, até hoje o bitcoin nem foi ainda largamente adotado como meio de transferência de direitos, sendo mais procurado como ativo financeiro altamente especulativo. 
Assim, não é possível praticar capitalismo usando bitcoins como meios de comando, e podemos dizer que o bitcoin fracassou em realizar os ideais de seus inventores. Apesar disso, em parte, o bitcoin se provou funcional como mecanismo de transferência de direitos furtivo à vigilância governamental. Por essa razão, foi adotado por milhões de usuários em todo o mundo como instrumento de operações financeiras "ilícitas", escapando de controles nacionais e internacionais.

Em função disso, na China, país no qual o governo mantém um dos mais rigorosos sistemas de controle financeiro do mundo na medida em que a soberania monetária é considerada um pilar fundamental da sua estratégia de desenvolvimento e expansão do poder nacional, o bitcoin se popularizou como objeto de especulação e meio para enviar e receber do exterior montantes equivalentes em dinheiro nacional que excedem os limites impostos às transações internacionais. Portanto, um meio para evadir divisas, fato que levou as autoridades a considerá-lo uma ameaça à segurança financeira nacional e a reprimir o seu uso.

Todavia, esse fato não as impediu de reconhecer as capacidades operacionais do bitcoin, vendo nas tecnologias que lhe servem de base o potencial para expandir os seus poderes de monitoramento e intervenção sobre as relações financeiras do país. Assim, procuraram adaptá-las em suporte ao renmimbi, culminando no recente lançamento, para um período de testes, do e-RMB - a sua representação digital, subordinada ao comando governamental. Entre os seus propósitos declarados estão: agilizar a execução das políticas monetárias; impedir transações ilícitas; e servir de base para um futuro sistema internacional de pagamentos alternativo ao atual, dominado pelo dólar e pela influência dos Estados Unidos. Portanto, justamente reforçar a soberania monetária e a segurança financeira do seu país.

Este artigo pretende investigar as razões desse fato. Na primeira seção, apresentaremos sucintamente as origens, objetivos e propriedades operacionais do bitcoin. $\mathrm{Na}$ segunda, trataremos da importância da soberania monetária na estratégia governamental da China tendo em vista seu desenvolvimento e poderio. $\mathrm{Na}$ terceira, trataremos da concepção de "segurança financeira" das autoridades chinesas. Na quarta, veremos como o emprego do bitcoin para especulação e evasão de divisas foi considerado por essas autoridades uma ameaça à segurança financeira do país. Na quinta, passaremos em revista as alegações e as ações dessas autoridades para assegurar o controle político sobre as tecnologias que dão base ao bitcoin, culminando na criação do "renmimbi digital". Finalmente, nas considerações finais, traçamos algumas conclusões a esse respeito. 


\section{Origens, objetivos e propriedades operacionais do bitcoin}

No livro "Bitcoin e criptomoedas: a utopia da neutralidade e a realidade política do bitcoin" (Ed. UFRJ), analisamos o bitcoin e as criptomoedas sob as perspectivas da teoria política e de teorias monetárias como a "Cartal" e a da "Moeda-Crédito". Nele, afirmamos considerar os aspectos "técnicos" dessas invenções na medida em que se revelassem importantes para orientar as nossas reflexões sobre as suas propriedades e consequências políticas.

Assim, vamos recapitular os argumentos e as conclusões apresentadas nesse trabalho que vem a ser a base do que desenvolvemos aqui.

$\mathrm{O}$ bitcoin entrou em funcionamento em janeiro de 2009. Encontrava-se no ápice a crise financeira que então atingia o capitalismo internacional, possivelmente a maior e mais grave desde a "Grande Depressão" (ROUBINI e MIHM, 2010). Ao torná-lo disponível para o público, seu suposto criador, Satoshi Nakamoto personagem obscuro cuja real identidade permanece desconhecida - lançou um "white paper" descrevendo as razões que o haviam motivado e as suas propriedades operacionais. Naquele documento, Nakamoto declarou como seu principal objetivo criar o que chamou de "novo sistema de dinheiro eletrônico" capaz de realizar "pagamentos online [...] diretamente de uma parte para outra sem passar por uma instituição financeira". Ele consistiria num "sistema de pagamentos eletrônico baseado em prova criptográfica ao invés da confiança [institucional], permitindo a quaisquer partes transacionar diretamente uma com a outra sem a necessidade de uma terceira parte confiável" (NAKAMOTO, 2009, p. 1, traduções livres).

Em rigor, Nakamoto retirou a inspiração ideológica desse empreendimento dos grupos libertários chamados "Cypherpunks", muito ativos nos Estados Unidos no início da década de 1990, quando o uso da internet começava a se popularizar. Sucintamente, seus integrantes objetivavam promover a privacidade e as liberdades individuais contra instituições como governos e grandes corporações. Para isso, usando técnicas criptográficas ${ }^{3}$ e outras tecnologias informáticas, desejavam, entre outras coisas, criar uma forma de dinheiro inteiramente livre de controles e arbítrios governamentais (POPPER, 2015).

Com base nesses princípios, Nakamoto desenhou o bitcoin com as seguintes

\footnotetext{
${ }^{3}$ A criptografia consiste em "codificar a linguagem para manter uma mensagem secreta" (VIGNA; CASEY, 2016, p. 47, tradução livre).
} 
propriedades: 1) o uso da técnica Peer-to-Peer, estabelecendo comunicações diretas entre computadores pessoais e dispensando instâncias intermediárias centralizadas, administradoras do sistema; 2) prova criptográfica em vez de confiança institucional, tendo as regras de funcionamento do sistema inscritas no próprio software original; 3) um registro público de transações, de livre acesso por qualquer usuário em qualquer instante, administrado pelos seus computadores num processo chamado de "mineração"4, formando uma "base de dados mantida de modo comunitário" intitulada blockchain; 4) um "método democrático" de gerenciamento coletivo, no qual as regras originais só podem ser alteradas com a concordância da maioria simples da potência computacional dos seus usuários; e 5) um procedimento pré-programado e decrescente de emissão de bitcoins definido em 21 milhões de unidades até o ano de 2140 (NAKAMOTO, 2009, p. 3-8), com o objetivo de tornar impossível qualquer "política monetária" arbitrária, centralizada (VIGNA; CASEY, 2016, p. 136, traduções livres).

Assim, Nakamoto reivindicou ter criado uma "moeda eletrônica", definida como uma "cadeia de assinaturas digitais" estabelecendo uma sequência cronológica de transferências de propriedade inscritas num registro contábil eletrônico, assinalando e atestando uma "cadeia de posse" (NAKAMOTO, 2009, p. 2).

Nos anos subsequentes ao seu lançamento, o bitcoin tornou-se imensamente popular, sendo adotado por milhões de usuários em todo o mundo. Formou-se então uma ampla rede de entusiastas e conferencistas segundo os quais, resumidamente, o bitcoin oferece: 1) anonimato e privacidade, pois registra as operações, mas não identifica seus usuários; 2) descentralização, pois gerenciado por uma rede de computadores; 3) relações não institucionais, pois inexistem autoridades e instituições centralizadas responsáveis pela sua administração; 4) "neutralidade" política, pois as políticas monetárias e os arbítrios e interesses governamentais são eliminados pela programação "técnica", logarítmica, do software; 5) universalidade, posto que transfronteiriço e transnacional, imune aos controles, vigilância e ingerências governamentais; e 6) uma alternativa às "inerentemente mal administradas" moedas governamentais, estando destinado a substituí-las.

Com isso, eles alegam que o bitcoin é uma moeda plenamente privada e livre de constrangimentos e "manipulações" políticas, tendo inspirado a criação de

\footnotetext{
${ }^{4}$ Trata-se de uma "prova de trabalho", um complexo problema matemático apresentado pelo sistema cuja solução é solicitada aos computadores "mineradores". O computador que equacionar o problema mais rapidamente adiciona um novo bloco de informações ao blockchain e recebe novas unidades de bitcoin como "prêmio" pelo trabalho realizado. A "mineração" requer potência computacional elevada e disponibilidade abundante, a baixo custo, de energia elétrica.
} 
milhares de outras "criptomoedas". Por intermédio desses instrumentos, eles acreditam, será instaurado um verdadeiro "livre mercado global" (ANTONOPOULOS, 2016, 2017; EHA, 2017; POPPER, 2015; VIGNA; CASEY, 2016).

A princípio, poderíamos crer que a invenção do bitcoin havia realizado os intuitos libertários. Todavia, no já citado livro, afirmamos que essas pretensões não resistem à análise mais rigorosa dos fatos. Isso acontece porque, entre outras razões: 1) diversos usuários do bitcoin envolvidos com atividades ilegais foram identificados e detidos pelas autoridades de países como os Estados Unidos e a Austrália; 2) com o crescimento exponencial dos custos da "mineração", ela se tornou muito centralizada na China, enquanto a posse dos bitcoins já emitidos está extremamente concentrada num número muito reduzido de contas; 3) hoje, a imensa maioria das transações passa por corretoras, que funcionam como instituições centralizadoras e exigem a identificação dos seus clientes. Nelas, falhas operacionais, fraudes e ataques hackers são frequentes; e 4) na medida em que esses clientes utilizam moedas e sistemas de pagamentos convencionais, se sujeitam às regulamentações governamentais (KOSINSKI, 2020).

Além disso, com base no capítulo "A realidade política do bitcoin", podemos afirmar que o bitcoin não é dinheiro, pois, em resumo: 1) não possui poder de comando, nem pode representar preços nos seus próprios termos, como podem quaisquer moedas governamentais em seus limites políticos; 2) não tem como fazer o seu preço em si mesmo, que seria a sua taxa de juros, propriedade exclusiva do dinheiro, outra condição necessária para a prática do capitalismo, como é a do poder de comando; 3) não existem autoridades garantidoras da liquidez; 4) o fato de, até o momento, não ter reconhecimento jurídico de nenhum governo não o faz aceito em lugar algum como meio de liquidação de impostos ou de dívidas; e 5) não é utilizado para representar o preço de qualquer matéria-prima essencial, como o petróleo, não sendo por isso aceito nas relações internacionais mediadas por dinheiro.

Portanto, isso significa que, usando bitcoins, não podemos fazer o que uma moeda governamental, em rigor dinheiro de pleno direito e minimamente estável, normalmente faz. Consideramos, então, que o bitcoin seja um sistema de pagamentos, de transferência de direitos expressos nas moedas governamentais no Japão, o Parlamento o reconheceu em 2017 como "ativo" e "método de 
pagamento", mas não como "moeda legal"5. Mesmo assim, ele possui utilidade restrita aos indivíduos e empresas que voluntariamente decidam aceitá-lo. Além disso, é de alto risco, devido à extrema volatilidade dos seus preços. Por isso, é muito mais demandado como ativo financeiro altamente especulativo do que como meio de aquisição de bens e serviços.

Apesar disso, confirmamos naquele trabalho que de fato o bitcoin pode ser um mecanismo bastante efetivo para transferir direitos, principalmente entre países. Suponhamos que um indivíduo utilize reais para adquirir bitcoins através de uma corretora brasileira. A partir do momento em que ele tiver transformado seus reais em bitcoins, pode enviá-los de forma anônima e quase instantânea para qualquer outra conta bitcoin; pode, também, convertê-los em qualquer dinheiro de qualquer país onde existam corretoras ou máquinas de autoatendimento (ATM) para bitcoins.

Esquematicamente:

\section{$\mathrm{R} \$ \rightarrow$ corretora $\rightarrow$ bitcoins $\rightarrow$ corretora ou ATM $\rightarrow$ US $\$, €, £, ¥$, Sfr, etc.}

Fonte: elaboração própria.

Ou seja, uma vez que o dinheiro tenha sido transferido para dentro do sistema bitcoin, as autoridades brasileiras não podem rastrear nem coibir de imediato a sua movimentação. Ele pode facilmente ser enviado para fora do país.

Portanto, o bitcoin permite operações financeiras livres dos controles governamentais, pelo menos num primeiro momento. Assim, trata-se de um instrumento de fácil utilização para enviar direitos pro exterior (ou recebê-los de lá), possibilitando converter uma moeda governamental em outra rapidamente, ignorando impostos e restrições. Opera à margem dos mecanismos financeiros "regulares", contornando as regulações e trocas de informações entre autoridades nacionais e instituições internacionais, como o sistema SWIFT (ZARATE, 2013).

Em função dessa capacidade, o bitcoin logo chamou a atenção das autoridades dos Estados Unidos, onde foi visto como um meio propício para o financiamento do tráfico de entorpecentes e do terrorismo, para a lavagem de dinheiro e a violação das leis financeiras federais. Por isso, rapidamente criou-se naquele país uma estrutura regulatória que impôs rigorosa vigilância e regulamentos governamentais sobre as atividades privadas com bitcoins e outras criptomoedas, muito embora o seu emprego não tenha sido proscrito (KOSINSKI, 2020).

Por outro lado, essa capacidade também fez com que o bitcoin atraísse a

5JAPAN: The New Heart of Bitcoin. Coindesk. 2017. Disponível em: <https://www.coindesk.com/japan-new-heart-bitcoin/>. Acesso em: 18 de mar. de 2018. Traduções livres. 
atenção de governos como os da Venezuela, Irã e Coreia do Norte, que viram no seu emprego e no de outras criptomoedas a possibilidade de contornar as sanções financeiras que thes eram impostas pelos Estados Unidos e seus aliados, possibilitando a obtenção de divisas externas escassas. Outras autoridades, como os bancos centrais do Reino Unido e da China, viram na disseminação do uso do bitcoin uma ameaça à estabilidade financeira dos seus países. Porém, elas mesmas viram nas tecnologias que servem de base a ele, desde que adaptadas ao dinheiro governamental e sob controle político, possibilidades de ampliar os seus poderes de monitoramento e comando das relações financeiras dos seus países.

No capítulo intitulado "Razões e consequências das ações governamentais na China: é possível banir o bitcoin?", investigamos o caso desse país, objeto de interesse deste artigo. Então, analisamos as posições que o Banco Popular da China, o banco central chinês, adotou com relação ao bitcoin a partir das declarações dos seus principais dirigentes e dos regulamentos criados pela instituição para lidar com ele. Além disso, antecipamos as razões e objetivos pelos quais o banco havia se interessado na criação de uma moeda digital sob o seu controle e apresentamos as suas primeiras iniciativas com vistas a concretizá-la.

Vejamos, por isso, quais foram essas posições e os interesses que culminaram no desenvolvimento do e-RMB, o "renmimbi digital", assim como as razões e os objetivos apresentados pelas autoridades chinesas para justificá-lo.

\section{O papel central da soberania monetária na estratégia de desenvolvimento e poder nacional da China}

Nos assuntos monetários, assim como em muitos outros, os chineses foram pioneiros. Estiveram entre os primeiros a padronizar objetos metálicos como representações materiais do dinheiro, cunhando, desde o século VII a.C., moedas para pagar pela contratação de soldados mercenários (GRAEBER, 2011, p. 236). Inventaram também o papel-moeda, tendo sido os primeiros na sua "emissão sistemática" ainda no século IX. Marco Polo, que viveu na China (então sob domínio mongol) entre 1275 e 1292, descreveu o seu sistema monetário num capítulo das suas "Viagens" intitulado "Do tipo de papel-moeda emitido pelo Grande Khan e feito passar corrente através dos seus domínios". O veneziano o considerou tão sofisticado que, impressionado, afirmou que "certamente pode ser afirmado que o 
Grande Khan tem um comando mais extenso do tesouro do que qualquer outro soberano no universo" (DAVIES, 2002, p. 182-183).

Por razões como essas, ainda em 1149 foi publicado na China o Chhuan Chih ("Tratado sobre a Cunhagem"), o mais antigo trabalho numismático conhecido, antecedendo os ocidentais em quase 500 anos. Também na ldade Média, o cronista Ma Twan-lin teorizou sobre os abusos governamentais na emissão de papel-moeda e sobre as origens do valor do dinheiro:

[...] o papel nunca deve ser dinheiro [mas] apenas empregado como um sinal representativo do valor existente no metal ou produção... A princípio esse era 0 modo no qual o papel moeda era efetivamente usado entre mercadores. O governo, tomando emprestada a invenção dos indivíduos privados, queria fazer um dinheiro real do papel, e então o artifício original foi pervertido. (YULE apud DAVIES, 2002, p. 184, destaque do original)

Equívocos à parte, há muito os estudiosos e burocratas chineses elaboram sofisticadas reflexões sobre as questões monetárias. Durante a "Era Imperial" (221 a.C. - 1912 d.C.), a ideologia confuciana oficial considerava a moeda parte essencial da governança, um instrumento cuja administração adequada propiciava aos dirigentes "preservar a riqueza e os bens e desse modo regular as atividades produtivas do povo", organizar e comandar o trabalho realizado pela sociedade, trazendo prosperidade, paz e ordem para o "Domínio Subcelestial" (VIGNA; CASEY, 2016, p. 31).

Em rigor, essa concepção subsiste integralmente na China contemporânea. No artigo China: entre os Séculos $X X$ e XXI, Carlos $A$. Medeiros investigou os fundamentos das estratégias de desenvolvimento nacional adotadas naquele país a partir da vitória dos comunistas liderados por Mao Tse-Tung em 1949.

Então, em função da enorme população, grau muito baixo de desenvolvimento produtivo e reduzida disponibilidade de terras aráveis, o governo definiu como "metas estratégicas" a expansão da produção industrial e da produtividade agrícola. Com efeito, foram esses os pontos-chave das diretrizes governamentais da China no tempo de plena Guerra Fria em que confrontou a União Soviética e os Estados Unidos ao mesmo tempo (KISSINGER, 2011, p. 113) com plena consciência de que, em especial, a industrialização era uma "necessidade" fundamental para o aumento da capacidade bélica e da segurança nacional (MEDEIROS, 1999, p. 382-383).

Porém, não obstante a importância de discutir as primeiras décadas do novo regime e as avaliações controversas de suas políticas como a do "Grande Salto Adiante", empreendido a partir de 1958, os objetivos do nosso trabalho concentram- 
se num tempo seguinte a esse. Assim, saltamos aquele tempo em que o produto industrial chinês cresceu menos que o determinado pelas audaciosas (ou irrealistas) metas estabelecidas, a desorganização provocada pela migração de milhões de camponeses para as cidades levou a produção agrícola por habitante a declinar em quase um terço (Ibid., p. 384) e o resultado foi a morte de milhões de chineses por inanição (ROBERTS, 2012, p. 373-376), para alcançarmos o que tomamos como o ponto de virada na história chinesa, base para o que hoje a China desenvolve.

Foi em 1978, depois de um acirrado período de disputas pelo controle do Partido Comunista que se seguiu à "Revolução Cultural" e à morte de Mao, que o grupo comandado por Deng Xiaoping, veterano comissário militar da guerra revolucionária, alcançou a liderança suprema do país (VOGEL, 2011). Sob o mote "Reforma e Abertura", as posições de Deng foram apresentadas na Terceira Plenária do $11^{\circ}$ Comitê Central realizada em dezembro daquele ano, sendo adotados como linha oficial os princípios básicos das "Quatro Modernizações", que visavam desenvolver a agricultura, a defesa, a indústria e a ciência e tecnologia.

Em rigor, esse programa foi resumido em 1979 por Hua Guofeng, então Secretário-Geral do Comitê Central do Partido:

[...] concentrar esforços para elevar a produção agrícola [...] acelerar o crescimento das indústrias têxteis e leves [...] superar os elos fracos da nossa economia: carvão, petróleo e energia, serviços de transporte e comunicações, indústria de materiais de construção [...] encurtar a construção do capital, tentando obter os melhores resultados de investimento [...] desenvolver de forma vigorosa a ciência, a educação e a cultura, e acelerar o treinamento de pessoal para construção [...] continuar o bom desempenho na importação de tecnologia, fazendo uso de fundos externos, e lutar para expandir as exportações [...] dar passos decisivos e constantes para reformar a estrutura da gerência econômica [...] preservar a estabilidade dos preços básicos, reajustar aqueles 'errados', fortalecendo ao mesmo tempo o controle de preços [...] elevar o padrão de vida da população passo a passo com o crescimento da produção [...] continuar a obter bons resultados no planejamento familiar e no efetivo controle do crescimento populacional. (MEDEIROS, 1999, p. 398)

Embora Guofeng tenha sido destituído em seguida, essas diretrizes gerais da "modernização socialista" permaneceram (KISSINGER, 2011). Elas orientaram iniciativas como a permissão à entrada de capitais estrangeiros no país, estratégia conhecida como "um país, dois sistemas", formulada por Deng nos anos 1980, e que instituiu as "Zonas Econômicas Especiais" (ZEE). Essas zonas eram entrepostos litorâneos nos quais as empresas estrangeiras se estabeleceram, frequentemente em parcerias com empresas locais. Nessas áreas, elas desfrutavam de condições tributárias e cambiais especiais concedidas pelo governo, que objetivava ganhos crescentes de produtividade industrial, domínio de tecnologias avançadas e acesso 
às moedas governamentais estrangeiras (MEDEIROS, op. cit., p. 397).

Por outro lado, no resto da China permaneceu vigente a política "regular" caracterizada por elevadas tarifas sobre importações e centralização do comércio em empresas estatais, que exerciam o monopólio cambial e controlavam o comércio exterior com barreiras não-tarifárias e restrições à importação de diversos bens, salvaguardando o imenso consumo interno para as empresas nacionais.

Dessa forma, foram estabelecidos no país dois regimes segmentados: um de proteção do mercado interno e de controle dos movimentos de capital; e outro, limitado às ZEEs e voltado para a expansão do comércio exterior e promoção agressiva das exportações, desfrutando de isenções tributárias e alguma liberdade cambial (lbid., p. 401). As políticas monetárias e cambiais foram organizadas de acordo com esses objetivos: em 1984, arbitrou-se a desvalorização do renminbi, foi criado um entreposto oficial com câmbios administrados e outro, com cotações ainda mais baixas, de acesso restrito às empresas exportadoras das ZEE e estatais de comércio exterior. Esse arranjo foi mantido até 1994, quando as taxas de câmbio foram unificadas mediante nova desvalorização significativa do renmimbi e foi criada uma praça unificada de negócios com divisas, em Shanghai.

No entendimento de Medeiros, essas reformas engendraram uma "complexa estratégia" do governo chinês objetivando a "afirmação da soberania do Estado sobre o território e a população através do desenvolvimento econômico e modernização da indústria" (Ibid., p. 385), tendo como principal vetor de expansão o comércio exterior. O seu sucesso foi inquestionável: entre 1984 e 1995, as exportações chinesas em dólares cresceram à taxa de $17 \%$ ao ano, passando de apenas 0,75\% do total mundial em 1978 para 3\% em 1995 (lbid., p. 387). Já em 2016, alcançaram 13,15\%, fazendo da China a maior exportadora mundial, somando mais de dois trilhões de dólares ${ }^{6}$. Enquanto isso, de 1978 a 2016, o seu produto interno bruto em dólares passou de pouco menos de 150 bilhões para 11,2 trilhões, enquanto o per capita subiu de apenas 156 para 8.123 dólares $^{7}$, com a perspectiva de superar os 10 mil nos próximos anos (LI, 2018, p. 41).

Não obstante, é importante ressaltar que a condição indispensável para o êxito desse projeto politicamente orientado de desenvolvimento foi 0 controle absolutamente rigoroso e centralizado da moeda governamental e das finanças ${ }^{6}$ ORGANIZAÇÃO MUNDIAL DO COMÉRCIO (OMC). Disponível em: <http://stat.wto.org/CountryProfile/WSDBCountryPFView.aspx?Country=CN>. Acesso em: 2 de dez. de 2017.

7BANCO MUNDIAL. Disponível em: <https://data.worldbank.org/country/china>. Acesso em: 3 de dez. de 2017. 
nacionais pelas autoridades centrais. É um projeto que tem como elementos principais a manutenção por arbítrio político do câmbio real desvalorizado, promovendo a competitividade das exportações, e a inconversibilidade quase total do renminbi, que em todo o período foi mantido "totalmente subordinado" ao Banco Popular da China (MEDEIROS, op. cit., p. 406). Em outras palavras: o governo chinês não hesita em exercer sem reservas a sua soberania monetária.

Em rigor, essas condições permaneceram essencialmente as mesmas em tempos mais recentes, conforme discutido por Benjamin J. Cohen em Currency Power: Understanding Monetary Rivalry. Tratando das perspectivas de internacionalização ${ }^{8}$ da moeda chinesa, Cohen considerou que um dos "recursos de poder" indispensáveis para concretizá-la é o nível do desenvolvimento e abertura financeira do país (sendo os demais as dimensões do seu produto e comércio exterior, a sua influência diplomática e o "alcance" do seu poder militar). Isso se refere ao volume, diversidade, resiliência e facilidade de acesso aos ativos denominados na sua moeda, condições necessárias para que ela obtenha ampla aceitação, elevada liquidez e demanda internacional (COHEN, 2014, p. 132-133).

Para Cohen, a decisão de promover a internacionalização do renminbi foi tomada em 2006, quando o Banco Popular da China publicou o documento intitulado The Timing, Path and Strategies of RMB Internationalization. Nele, afirmou-se que havia "chegado a hora" de assumi-la como objetivo nacional, visando "elevar significativamente o status [...] a competitividade e a influência" do país e reduzir a sua vulnerabilidade às crises externas e à influência do dólar. Com isso, o governo pretendia "ter mais opinião" nas relações internacionais e desfrutar da "ascensão" na sua posição global de poder (COHEN, 2015, p. 216, traduções nossas).

Todavia, para Cohen, a China possui "uma das moedas mais hermeticamente controladas no mundo, encurralada por todas as formas de restrições de transações e controles de capitais" (Ibid., p. 217). Nos últimos anos, diversas medidas de relativo "relaxamento" das restrições foram adotadas, tais como: acordos bilaterais

\footnotetext{
"Sucintamente, a "internacionalização" diz respeito ao emprego de uma moeda fora do seu país de origem nas transações entre dois países estrangeiros ou no interior de outros (nesse caso, "substituição" monetária). Esse uso pode se dar enquanto unidade de conta para o faturamento comercial e denominação de ativos de reserva pelas iniciativas privadas ou como reserva cambial, meio de intervenção e indexação para taxas de câmbio por governos (COHEN, 2014, p. 127). Para o país emissor da moeda internacionalizada, as principais vantagens são usá-la para realizar pagamentos ao exterior sem precisar exportar, receber investimentos estrangeiros ou contrair empréstimos em moedas estrangeiras. Além disso, com o crescimento da demanda externa pela sua moeda, o governo aumenta a sua capacidade de endividamento e reduz os seus custos. Assim, atribuiu-se ao governo dos Estados Unidos um "privilégio exorbitante" por controlar e emitir a moeda preferencial de denominação, padrão de referência e uso em contratos, investimentos, no comércio e nas finanças internacionais (EICHENGREEN, 2011).
} 
para o fornecimento da moeda chinesa para outros bancos centrais; criação de centros de compensação de transações denominados em yuans em diversos países; autorização para abertura de contas correntes e emissões de títulos denominados em yuans em algumas grandes praças financeiras no exterior; e permissão de compras de ativos financeiros chineses por estrangeiros, embora sujeitas a "cotas estritas, controles administrativos e [...] muito limitadas no total" (Ibid. p. 227).

No entanto, o ritmo dessa liberalização permaneceu "lento", "cauteloso" e "incremental". Até mesmo as instituições financeiras de Hong Kong só foram autorizadas a abrir contas em yuans a partir de 2010. Por essas razões, de maneira geral, o renmimbi "permanece em larga medida inconversível tanto para residentes quanto para não residentes" (Ibid., p. 227). Até mesmo as políticas "moderadas" de conversibilidade, que facilitariam a sua adoção no exterior ainda que "minimizando as vulnerabilidades resultantes", não foram adotadas (Ibid., p. 233). Elas permitiriam aos residentes movimentar capitais mais facilmente, reduzindo o controle das autoridades sobre as condições financeiras.

Desse modo, evidencia-se que a internacionalização do renminbi ainda não é considerada prioritária. Entre promover maior liberalização e manter restritos o acesso e o uso da moeda nacional para conservar estrito controle centralizado, as autoridades chinesas optam pela última.

Em acordo com Medeiros, na visão de Cohen esse fato também está estritamente relacionado à importância vital dos controles financeiros para o funcionamento da estratégia chinesa de desenvolvimento. Trata-se do pilar central do chamado "Consenso de Beijing", uma diretriz administrativa "distinta" na qual "uma burocracia central incontestável" mantém "controle central" sobre atividades privadas parcialmente liberalizadas, preservando para si um "papel de liderança em promover e orientar a acumulação capitalista" (Ibid., p. 234). Nesse "modelo chinês":

[...] nada é mais crítico para o controle bem-sucedido do que a habilidade para gerenciar as condições monetárias e financeiras. Internamente, isso significa autoridade direta sobre as taxas de juros e a disponibilidade de crédito, capacitando o Estado a alocar recursos para mutuários favorecidos e minimizar seus próprios custos de financiamento. A autoridade é exercida através de depósitos regulados e taxas de empréstimo, orientação quantitativa do crédito e racionamento do mercado de títulos. Internacionalmente, controle significa uma conta de capital fechada e taxa de câmbio gerenciada. (Ibid., p. 235)

Em resumo, por mais que variem as suas diretrizes políticas, as autoridades chinesas não abrem mão da sua soberania monetária, por meio da qual comandam sem restrições o desenvolvimento nacional. Por essas razões, elas entendem as 
finanças como uma questão de segurança nacional. A afirmação de que "uma invasão de moeda estrangeira [...] pode ser tratada como o equivalente a uma agressão militar" (COHEN, 2014, p. 167) é particularmente real no seu imaginário.

\section{A concepção chinesa de "segurança financeira"}

No documento Research Findings on the Path of China's Peaceful Rise, elaborado por equipes do Comitê Executivo do Partido Comunista da China e do China Reform Forum, as autoridades chinesas delinearam as "oportunidades", os "perigos" e os "desafios" enfrentados pelo país nas primeiras décadas do século XXI tendo como objetivo garantir a sua segurança, a continuidade do seu desenvolvimento e a sua ascensão internacional, de modo a alcançar o "rejuvenescimento nacional" e tornar-se uma "sociedade moderadamente próspera" na década de 2020 (ZHENG, 2018).

Foi nesse sentido que "questões estratégicas" centrais foram destacadas para serem resolvidas, entre elas a da "segurança financeira". Vejamos, pois, o que o documento revela sobre essa política, considerada condição fundamental para alcançar aqueles objetivos.

Com clara orientação pelo pensamento de Marx, a primeira questão estratégica considerada foi a da manutenção do desenvolvimento e da expansão das forças produtivas nacionais. Foi a preocupação com o fato de a China ser capaz ou não de "manter o ímpeto de reforma para sustentar um desenvolvimento forte e garantir que a economia nacional continuará a expandir" de forma "rápida, harmoniosa e saudável" (ZHENG, 2018, p. 15, traduções livres). Como justificativas, foram indicadas a necessidade de gerar até 14 milhões de empregos anualmente para absorver a expansão da força de trabalho e a "competição" no âmbito internacional, exigindo a construção do que foi chamado de "poder nacional compreensivo":

Essa competição não é apenas econômica; também [...] entre sistemas sociais e ideologias. Se nós não ganharmos [...] em crescimento e qualidade, será difícil provar convincentemente para o mundo a supremacia do socialismo com características chinesas. (Ibid., p. 15)

Além disso, enfatizou-se que "resolver todos os problemas da China depende da questão crucial do desenvolvimento" e que "manter o crescimento rápido [...] é inerentemente o maior fator na segurança econômica" (lbid., p. 15).

A segunda questão levantada foi assegurar a coordenação das "necessidades materiais e culturais" do país, decorrentes do crescimento da população de 1,3 para 
1,5 bilhão de habitantes, com o desenvolvimento ambiental, dos recursos e da produtividade. Apontou-se a enorme carência em "energia, alimentos, matérias primas e água", necessidades de abastecimento causadas pelo próprio desenvolvimento, especialmente o industrial. Em relação à média mundial, a China possui apenas $8 \%$ do petróleo por habitante, $25 \%$ da água potável, $40 \%$ das terras agricultáveis, $4 \%$ do gás natural, $25 \%$ do cobre e $9 \%$ do alumínio. Assim, afirmou-se a urgência em "assegurar a estabilidade no abastecimento de longo prazo dos recursos estratégicos" e "conduzir as revoluções" nas novas tecnologias (como as da informação), considerando que "esse não é meramente um problema econômico; é parte da segurança [...] nacional" (Ibid., p. 16).

A terceira questão estratégica apontada indica preliminarmente a concepção de "segurança financeira". Ela se refere à capacidade da China de "garantir o suprimento de capitais necessários para resolver as dificuldades de larga escala do desenvolvimento" (Ibid., p. 17). Indicou-se a posição do país como segundo maior receptor global de investimentos estrangeiros e a sua "dependência" desses capitais. A solução proposta foi promover reformas e criar mecanismos de gerenciamento para o melhor aproveitamento da poupança doméstica. Com isso, afirmou-se que haveria melhor coordenação entre capitais nacionais e estrangeiros, reduzindo a vulnerabilidade nacional ao "perigo à espreita" da fuga de capitais.

Outra questão levantada foi a manutenção da soberania nacional ao mesmo tempo em que a China aprofunda a sua participação no que o documento chamou de "globalização econômica", uma rede global de capitalismos nacionais descrita como projetada e liderada pelos Estados Unidos e seus aliados, controlada por corporações transnacionais ocidentais e manipulada em seu favor. $\mathrm{Na}$ visão das autoridades chinesas, esse fato amplia o "escopo da segurança" para questões como sociedade, meio ambiente e cultura, tornando o fortalecimento da soberania, considerada a "fundação insubstituível para a sobrevivência e o desenvolvimento de uma nação", um objetivo "ainda mais amplo e urgente" (Ibid., p. 20-21).

Diante disso, indicou-se como "absolutamente necessária" a construção de um sistema de defesa nacional "forte", capaz de "proteger os interesses estratégicos" num momento em que a "competição internacional está se intensificando". Para isso, recomendou-se a ampliação dos investimentos militares, a reequipagem das Forças Armadas e a reforma doutrinária. Discutiu-se também a acomodação da ascensão do país na ordem internacional vigente e a necessidade de reformá-la, enfrentando o "hegemonismo" e o “unilateralismo" dos Estados Unidos (Ibid., p. 22-24). 
A esse respeito, afirmou-se que "não há dúvidas que a China deve se proteger contra ser cercada pelos Estados Unidos e seus aliados" (Ibid., p. 23-24), citando como exemplo o abastecimento de petróleo, mais da metade do qual originário do Oriente Médio e $80 \%$ transitando pelo estreito de Malaca, duas regiões altamente vulneráveis ao poderio militar estadunidense. Os mares do Sul da China e da China Oriental também foram apontados como áreas sensíveis a esse "cerco", exigindo "o estabelecimento de uma estratégia marítima correspondente" focada na afirmação da soberania sobre as águas territoriais, na diversificação das rotas de abastecimento e na constituição de uma força aeronaval adequada (lbid., p. 26-27).

Outras questões, como as de Taiwan e Hong Kong e a "sinicização do marxismo", também foram elencadas. Porém, destacamos que a concepção de segurança financeira esboçada nesse documento oficial foi detalhada pelo atual presidente chinês, Xi Jinping. Em discurso proferido em julho de 2017, reiterando a necessidade de prosseguir o desenvolvimento produtivo e tecnológico e a ampliação do poder militar com vistas a alcançar o "rejuvenescimento" nacional, Xi afirmou que:

\begin{abstract}
As finanças são uma competitividade central de uma nação. A segurança financeira é um componente importante da segurança nacional, e o sistema financeiro é a base para o desenvolvimento econômico e social. A liderança do Partido Comunista sobre as finanças tem que ser fortalecida. Seguindo as linhas gerais de fazer progressos constantes e a lei de desenvolvimento financeiro, devemos [...] servir à economia real, prevenindo e controlando riscos financeiros e levando adiante reformas financeiras. Devemos inovar e melhorar o controle financeiro, o sistema empresarial moderno para negócios financeiros e o mercado financeiro, construir uma estrutura de supervisão financeira moderna, continuar a transformar o modelo de crescimento das finanças, fortalecer o estado de direito no setor financeiro, garantir a segurança financeira do Estado e facilitar o desenvolvimento sólido, circular e saudável da economia e das finanças. (XI, 2017, p. 304, tradução livre)
\end{abstract}

Em suma, manter o desenvolvimento acelerado é um imperativo para as autoridades chinesas. Na sua visão, trata-se da condição indispensável para: 1) assegurar a criação de milhões de novos empregos anualmente, garantindo a estabilidade social e política do país e a legitimidade do Partido e do regime; 2) alcançar a liderança tecnológica; 3) ampliar e consolidar o poderio militar, fundamental na competição num sistema interestatal no qual os chineses se veem sob cerco crescente pelos Estados Unidos; e 4) garantir a segurança nacional.

Não obstante, para isso, a segurança financeira é considerada um objetivo estratégico central. Isso significa assegurar a autonomia do Estado chinês em dispor do enorme volume de recursos financeiros necessários para sustentar altas taxas de investimento, independentemente dos capitais estrangeiros. Em outras palavras, 
garantir o comando do governo sobre o seu dinheiro, sobre as operações que o têm como referência e sobre a capacidade produtiva do país. Assim:

[...] desponta no mundo a China num ritmo de desenvolvimento que pode servir de exemplo, especialmente por ter o iuan como moeda não conversível com a qual o governo chinês se faz o comandante supremo de um sistema monetário não subordinado. [...] o caso da China é o da atual inserção de uma população em torno de $20 \%$ da humanidade, que é consumidora crescente num país de consequente crescimento de consumo energético, com governo e moeda completamente fora do controle do FMI, dos Estados Unidos e das demais grandes potências. (FERREIRA FILHO, 2015, p. 412-413)

Em suma, segurança financeira é a prerrogativa governamental de comandar integralmente o dinheiro, distribuí-lo sem restrições. Todavia, o bitcoin representa um instrumento cujas propriedades são antitéticas a essas diretrizes. O quadro abaixo explicita essas diferenças:

\begin{tabular}{|c|c|}
\hline Bitcoin & Renmimbi/Yuan \\
\hline Privado, anônimo & Estatal, intensamente controlado \\
\hline Descentralizado, não institucional & Fortemente centralizado \\
\hline Sem política monetária; "neutro" & $\begin{array}{c}\text { Política monetária ativa, subordinada } \\
\text { aos objetivos governamentais }\end{array}$ \\
\hline Transnacional, transfronteiriço & Nacionalismo e insulamento monetário \\
\hline Sem restrições operacionais & $\begin{array}{c}\text { Restrições rigorosas para transações } \\
\text { cambiais e internacionais }\end{array}$ \\
\hline
\end{tabular}

Fonte: elaboração própria.

Essa é a razão pela qual as autoridades chinesas, zelosas da sua soberania monetária, do seu dinheiro, não tardaram a ver o bitcoin como uma ameaça à segurança financeira do seu país.

\section{O emprego especulativo, a evasão de divisas por meio do bitcoin e a ameaça à segurança financeira da China}

Os chineses não tardaram a descobrir o potencial do bitcoin. Afinal, as autoridades locais impõem severas restrições à manipulação de moedas estrangeiras, como o limite de 50 mil dólares anuais em remessas e compras no exterior (VIGNA; CASEY, 2016, p. 195-196). Com isso, os residentes no país são incentivados (ou constrangidos, dependendo do ponto de vista) a investir seus excedentes monetários na própria China, importante providência do governo para dirigir a poupança nacional para os seus objetivos.

Dessa forma, logo emergiu uma "grande e entusiástica" comunidade chinesa de compradores e "mineradores" de bitcoins. Em junho de 2011 foi criada a BTC 
China, corretora privada que permitia usar yuans para adquiri-los. A demanda local cresceu rapidamente e, em meados de 2013, a empresa já movimentava diariamente mais de 100 mil unidades (POPPER, 2015, p. 267).

Com isso, cresceu a especulação e o preço do bitcoin em yuans subiu quase 10 vezes em dois meses. Diante disso, o Banco Popular da China e outras autoridades reguladoras declararam, a princípio, considerar o bitcoin um tipo de "ativo" ou "commodity digital" cuja compra e venda no país seria permitida, embora sob risco dos investidores. Todavia, rejeitaram reconhecê-lo como dinheiro, afirmando que ele "carecia da mais importante característica [...]: a cobertura governamental" (Ibid., p. 274). E determinaram que as companhias financeiras "regulares" não poderiam lidar com ele direta ou indiretamente, recebendo ordens para encerrar as contas das corretoras (lbid., p. 284).

Assim, a BTC China reduziu em mais de dez vezes o seu volume transacionado e a mineração tornou-se a forma preferencial de obter os bitcoins. $A$ China fornece em abundância os dois insumos essenciais para a "produção" dos bitcoins, energia elétrica e equipamentos eletrônicos. Assim, pode ofertar a baixo custo um ativo que tem demanda no exterior, e empresários locais começaram a montar grandes "fábricas" de mineração próximas a usinas hidroelétricas em regiões remotas. Logo se tornaram líderes mundiais na mineração, obtendo mais da metade das novas unidades (lbid., p. 364). As autoridades não coibiram essas atividades.

Em 2015, em seguida à forte desvalorização da bolsa de valores de Shanghai, recrudesceu o interesse dos chineses pela aquisição dos bitcoins. Então, eles começaram a adotar formas de driblar as restrições governamentais, como os chamados over-the-counter trades, nos quais compradores e vendedores realizam transações diretamente, se comunicando através de aplicativos de mensagens instantâneas. Outra solução comum foi o estabelecimento de redes privadas virtuais, que utilizam protocolos criptografados.

Essas práticas deram origem a um ativo "comércio underground" de bitcoins. Subitamente, a moeda chinesa tornou-se dominante no sistema como referência das transações, chegando a mais de $95 \%$ do volume total no final do ano, embora já tivesse superado o dólar desde o início de $2014^{9}$. Os preços do bitcoin voltaram a crescer rapidamente, de uma média de 1.500 yuans em meados de 2015 para quase

${ }^{9}$ ONE chart shows how the Chinese bitcoin market collapsed in 2017. Business Insider, 2017. Disponível em: <http://markets.businessinsider.com/currencies/news/morgan-stanley-chart-on-yuandollar-yen-euro-volumes-in-bitcoin-market-2017-12-1012338966>. Acesso em: 6 de fev. de 2018. Traduções livres. 
7.000 um ano mais tarde. Enquanto isso, as reservas internacionais do país caíram $8 \%$ e o yuan se desvalorizou em relação ao dólar, aumentando o interesse no bitcoin como forma de enviar valores para o exterior ${ }^{10}$.

Diante desse fato, em janeiro de 2017, o Banco Popular da China anunciou uma investigação para verificar "possível manipulação de mercado, lavagem de dinheiro, financiamento não autorizado e outras questões"11 através de operações com bitcoins. Após as inspeções, as corretoras promoveram "atualizações" nos seus sistemas de segurança tendo em vista a adequação às regulações financeiras, anunciando a suspensão temporária dos resgates de bitcoins (que durou até julho) ${ }^{12}$. Embora a parcela do yuan na rede tenha declinado para menos de $25 \%$ do total, os preços continuaram subindo, alcançando 30.000 no início de setembro, mostrando que a procura dos chineses pelos bitcoins continuava a crescer.

Assim, em setembro de 2017, o banco emitiu uma nova regulação ${ }^{13}$ que considerou "ilegais e disruptivos para a estabilidade econômica e financeira" a manipulação de criptomoedas, demonstrando preocupação com eventual "agitação social" decorrente de perdas com "atividades financeiras não reguladas" e com o seu possível uso por "funcionários públicos corruptos" para transferir recursos ao exterior ${ }^{14}$. Então, invocando leis financeiras, de segurança cibernética e telecomunicações, determinou: 1) que o bitcoin e as demais criptomoedas eram ilegais, pois "não são emitidos pela autoridade monetária" e não possuem "nenhuma propriedade legal como faz a moeda fiduciária", não devendo "circular no mercado monetário"; 2) que "todos os tipos" de atividades com tais instrumentos mantidas por organizações e indivíduos deveriam "cessar imediatamente"; 3) que todas as corretoras interrompessem as operações de compra e venda de criptomoedas e a

${ }^{10} \mathrm{ONE}$ country dominates the global bitcoin market. Business Insider, 2017. Disponível em: <http://www.businessinsider.com/bitcoin-trading-china-yuan-remnibi-2017-1>. Acesso em: 6 de fev. de 2018. Traduções livres.

${ }^{11}$ BITCOIN slides after China central bank launches investigation. Reuters, 2017. Disponível em: <https://www.reuters.com/article/us-markets-bitcoin-pboc/bitcoin-slides-after-china-central-banklaunches-investigation-idUSKBN14V10B>. Acesso em: 6 de fev. de 2018. Traduções livres.

12 BEIJING bans bitcoins, but when did it all go wrong for cryptocurrencies in China? South China Morning Post, 2018.2 Disponível em: $<$ http://www.scmp.com/news/china/economy/article/2132119/beijing-bans-bitcoin-when-did-it-all-gowrong-cryptocurrencies>. Acesso em: 6 de fev. de 2018. Traduções livres.

${ }^{13}$ CHINA'S ICO ban: a Full Translation of Regulator Remarks. Coindesk, 2017. Disponível em: <https://www.coindesk.com/chinas-ico-ban-a-full-translation-of-regulator-remarks/>. Acesso em: $1 \mathrm{de}$ dez. de 2017. O texto original está disponível em: <http://www.circ.gov.cn/web/site0/tab6554/info4080736.htm>. Traduções livres.

${ }^{14}$ WHAT happened to initial coin offerings in China? South China Morning Post, 2018. Disponível em: <http://www.scmp.com/tech/china-tech/article/2132319/what-happened-initial-coin-offerings-china>.

Acesso em: 6 de fev. de 2018. Traduções livres. 
sua troca por moedas governamentais; 4) que as instituições financeiras "regulares" deixassem de realizar quaisquer tipos de operações relacionadas às criptomoedas; e 5) que o público e as instituições observassem estritamente as leis e regulações, zelando pela estabilidade financeira e relatando quaisquer violações às autoridades.

Mesmo assim, o preço do bitcoin continuou em forte ascensão, ultrapassando 125.000 yuans em meados de dezembro. Então, a rede de televisão estatal China Central Television atribuiu o fenômeno às negociações over-the-counter, exibindo vídeos produzidos por corretoras em clara violação das regulações governamentais que tinham proibido as suas atividades ${ }^{15}$.

Dessa forma, em janeiro de 2018, o banco central ordenou mais uma vez às instituições financeiras que interrompessem a prestação de todos os serviços bancários ou financiamento para as atividades relacionadas às criptomoedas, ao passo que o Leading Group of Internet Financial Risks Remediation, principal regulador chinês das atividades financeiras na internet, solicitou aos governos locais que orientassem as empresas de "mineração" a abandonar as suas atividades"

Enquanto a última medida não foi efetivamente aplicada, no mês seguinte, o banco central anunciou uma nova determinação ${ }^{17}$ : o bloqueio completo no país de todos os sites relacionados às criptomoedas, inclusive estrangeiros, reconhecendo que as medidas anteriores haviam falhado em "erradicar completamente" as atividades e que, após o fechamento das corretoras domésticas, os chineses haviam acorrido às plataformas no exterior para continuar as suas operações.

Não havia mais dúvidas de que o bitcoin e as criptomoedas em geral eram considerados uma ameaça à segurança financeira do país e que as autoridades objetivavam extinguir completamente as suas atividades no território nacional.

\section{Os planos governamentais para o controle político das criptomoedas e a criação do "renmimbi digital"}

\footnotetext{
${ }^{15} \mathrm{CHINA}$ State TV: OTC Bitcoin Platforms May Violate Law. Coindesk, 2017. Disponível em: $<\mathrm{https}$ ://www.coindesk.com/china-state-tv-otc-bitcoin-platforms-may-violate-regulation/>. Acesso em: 7 de fev. de 2018. Traduções livres.

${ }^{16}$ BEIJING bans bitcoins, but when did it all go wrong for cryptocurrencies in China? South China Morning Post, 2018. Disponível em:

$<$ <ttp://www.scmp.com/news/china/economy/article/2132119/beijing-bans-bitcoin-when-did-it-all-gowrong-cryptocurrencies>. Acesso em: 6 de fev. de 2018. Traduções livres.

${ }^{17}$ CHINA to stamp out cryptocurrency trading completely with ban on foreign platforms. South China Morning Post, 2018. Disponível em: <http://www.scmp.com/business/bankingfinance/article/2132009/china-stamp-out-cryptocurrency-trading-completely-ban>. Acesso em: 6 de fev. de 2018. Traduções livres.
} 
O motivo principal das autoridades chinesas para reprimir o uso do bitcoin e das demais criptomoedas foi a sua falta de controle sobre esses sistemas. Porém, isso não as impediu de reconhecer as suas propriedades operacionais, nem de crer que as suas tecnologias não pudessem ser adotadas em combinação com 0 renmimbi - portanto, sob o seu comando e em favor dos seus interesses e objetivos.

Desse modo, em fevereiro de 2016, o então governador do Banco Popular da China, Zhou Xiaochuan, apresentou numa entrevista ${ }^{18}$ as posições da instituição a respeito das "moedas digitais", assim como dos planos para a possível instituição de um "renmimbi digital" (BANCO POPULAR DA CHINA, 2016, traduções livres).

$\mathrm{Na}$ ocasião, Zhou afirmou que o papel-moeda "carece de suporte de alta tecnologia", sendo uma "tendência irresistível" que seja substituído por "novos produtos e tecnologias com maior segurança e custo mais baixo". Com os avanços da internet e dos sistemas de pagamentos, ele considerou "necessário estabelecer o sistema de emissão e circulação de moeda digital" com vistas a "ajudar a construir a infraestrutura financeira e melhorar a qualidade e eficiência" das atividades produtivas no país. Então:

Da perspectiva do banco central, a moeda digital deve ser projetada de tal forma que possa proteger melhor a privacidade das pessoas, mas também precisamos prestar atenção à segurança e à ordem sociais. Precisamos manter alguns instrumentos investigativos necessários prontamente disponíveis para lidar com atividades criminosas. Um equilíbrio precisa ser atingido entre proteger a privacidade e reprimir as atividades ilegais. Diferentes preferências entre esses dois motivos levarão a orientações tecnológicas diferentes para a moeda digital. (Ibidem)

Em seguida, Zhou elencou os princípios orientadores dessa moeda:

O primeiro é conveniência e segurança. Segundo, como mencionado anteriormente, um equilíbrio precisa ser atingido entre proteger a privacidade, manter a ordem social e reprimir atividades ilegais, especialmente preservando os instrumentos necessários para combater a lavagem de dinheiro e o financiamento de atividades terroristas. Terceiro, ela deve ser propícia à operação e transmissão eficientes das políticas monetárias. Quarto, o controle sobre a soberania monetária deve ser mantido. A moeda digital pode ser convertida livremente, mas a sua conversibilidade também será controlada. Pensamos, portanto, como curso legal, a moeda digital tem que ser emitida pelo banco central. A emissão, circulação e transação da moeda digital vão seguir os mesmos princípios de administração da moeda tradicional. (Ibidem)

Além disso, o governador enfatizou que "nós ainda precisamos ajustar o mecanismo de criação [...] e oferta de moeda" e que o "principal objetivo" da criação da moeda digital "é substituir a moeda física de maneira a reduzir os custos de emitir

18 BANCO POPULAR DA CHINA. Transcript of Governor Zhou Xiaochuan's Exclusive Interview with Caixin Weekly, 2016. Disponível em: <http://www.pbc.gov.cn/english/130721/3017134/index.html>. Acesso em: 8 de fev. de 2018. Traduções livres. 
e circular papel-moeda tradicional e melhorar a conveniência" (Ibidem).

Ademais, Zhou reiterou que o banco central considerava manter "integralmente a atual estrutura de política monetária, o mecanismo de criação e suprimento de dinheiro e os canais de transmissão da política monetária" no projeto da moeda digital. Seu funcionamento, tal qual o da moeda tradicional, se basearia no "sistema binário 'banco central-bancos comerciais'", as diferenças se restringindo aos métodos eletrônicos de distribuição e entesouramento. Com isso, ele afirmou crer que a "segurança e eficiência" dos processos financeiros no país seriam "significativamente melhoradas". Por outro lado, as tecnologias anti-falsificação da moeda digital, baseadas em técnicas criptográficas, seriam "segredos nacionais"; e em se tratando de "uma moeda digital controlada pelo banco central", uma "combinação de medidas tecnológicas e projeto institucional, assim como leis e regulações, serão aplicadas para assegurar a segurança do seu sistema operacional. Isso difere do bitcoin desde o começo" (lbidem).

Alguns meses depois, o então vice-governador do banco, Fan Yifei, publicou um ensaio ${ }^{19}$ no qual declarou que "a melhor forma de tirar vantagem" dessas inovações é fazendo com que os bancos centrais assumam a "liderança, tanto supervisionando as moedas digitais privadas quanto desenvolvendo o seu próprio curso legal digital". Segundo ele, este esforço vinha sendo empreendido principalmente com vistas a "manter a estabilidade financeira, encorajar a inovação e supervisionar adequadamente a emissão e circulação dessas novas moedas", além de "estabelecer estruturas institucionais sensatas e controles macroprudenciais".

Além disso, Fan afirmou que as moedas digitais possuíam grande potencial para "reduzir custos, aumentar eficiência e possibilitar ampla gama de novas aplicações". Todavia, também apresentavam "defeitos fundamentais" como a instabilidade do seu valor, credibilidade "fraca", baixa aceitação e potencial para "externalidades negativas". No seu entendimento, uma moeda digital emitida pelo banco central "poderia ajudar a resolver muitos desses problemas", pois seria "garantida pelo crédito estatal", compatibilizando aplicações "com maior alcance, conveniência e segurança". Diante disso, declarou crer que "os bancos centrais terão que considerar cuidadosamente como controlar a emissão para assegurar um valor estável, que será um fator-chave conforme as autoridades monetárias competem para desenvolver a abordagem mais efetiva".

\footnotetext{
${ }^{19} \mathrm{ON}$ Digital Currencies, Central Banks Should Lead. Bloomberg, 2016. Disponível em: <https://www.bloombergquint.com/onweb/2016/09/01/on-digital-currencies-central-banks-shouldlead>. Acesso em: 8 de fev. de 2018. Traduções livres.
} 
Sendo assim, em junho de 2017, o Banco Popular da China estabeleceu o seu Digital Currency Research Institute, recrutando especialistas em encriptação, blockchain e big data. Em outubro, o seu diretor Yao Qian declarou ${ }^{20}$ que a instituição concebia a moeda digital governamental como "forma de estabilizar a moeda fiduciária doméstica [e] proteger melhor a condição financeira do país". Isso porque, segundo ele, "o valor das criptomoedas como o bitcoin decorre primariamente da especulação [...]. Será um desastre reconhecê-lo como uma moeda real. E a falta de uma ancoragem de valor [...] determina que o bitcoin não poderá ser um [valor] real”.

Além disso, Yao criticou a "natureza deflacionária" do bitcoin como um "obstáculo" para o seu sucesso. Em contrapartida, argumentou que uma moeda digital estatal "cria valores tangíveis", constituindo uma "obrigação do governo emitida para o público [...] apoiada pela credibilidade do soberano". Assim, afirmou não ver justificativas para que a "ideologia do blockchain e das tecnologias de registros distribuídos" impedisse os governos de criar moedas digitais.

Já em novembro de 2017, em fórum realizado em Beijing, Yao citou ${ }^{21}$ como objetivos gerais da moeda digital governamental "ajudar a reduzir custos de transação, estender serviços financeiros às áreas rurais e aumentar a eficiência das políticas monetárias". Na ocasião, afirmou também que "o desenvolvimento da economia digital precisa mais do que nunca da moeda eletrônica emitida pelo banco central" por ser um objeto "mais fácil de rastrear", fato que permitiria ao banco "monitorar a sua velocidade e paradeiros [...] e melhorar as suas políticas monetárias". Para ele, ela será a "jóia da coroa" das novas tecnologias financeiras, com amplas implicações no futuro do sistema financeiro mundial, acrescentando o big data e a inteligência artificial como técnicas de aperfeiçoamento da análise de riscos sistêmicos e fortalecimento da intervenção regulatória pelos governos.

Em suma, as declarações dessas autoridades explicitaram o propósito de criar uma moeda digital sob comando governamental, subordinada aos seus objetivos de política monetária, fiscal e de desenvolvimento, com vigilância das transações privadas, enfim, claras providências de controle social.

\footnotetext{
20 PBOC Digital Currency Director Calls for Centralized State Cryptocurrency. Coindesk, 2017. Disponível em: <https://www.coindesk.com/pboc-digital-currency-director-calls-centralized-statecryptocurrency/>. Acesso em: 8 de fev. de 2018. Traduções livres.

${ }^{21}$ CHINA'S central bank is developing its own digital currency, even as it bans bitcoin and private cryptos. South China Morning Post, 2017. Disponível em: <http://www.scmp.com/business/companies/article/2118468/chinas-central-bank-studying-its-owndigital-currency-even-it>. Acesso em: 20 de fev. de 2018. Traduções livres.
} 
Finalmente, em abril de 2020, o Banco Popular da China anunciou ${ }^{22}$ o lançamento da sua moeda digital, intitulada e- $R M B$, para testes em metrópoles como Shenzhen, Suzhou, Chengdu e no distrito de Xiong'an, em Beijing. Então, parte dos funcionários públicos dessas cidades passaram a receber seus salários nesse "renmimbi digital", a ser testado como meio de subsidiar os transportes públicos, o comércio e o abastecimento de alimentos em algumas daquelas cidades.

Ao contrário das plataformas para pagamentos digitais já existentes e muito populares no país, como Alipay e WeChat Pay, o e-RMB substitui o uso da moeda oficial, a representando digitalmente sob a paridade de 1=1. Com o seu lançamento, o banco central afirmou pretender "otimizar e melhorar" o funcionamento do sistema com vistas a, no futuro, generalizar o seu uso e ser capaz de monitorar em tempo real os fluxos monetários, elevando substancialmente a sua capacidade de supervisionar e manipular as condições financeiras do país.

Já o veículo estatal China Daily afirmou ${ }^{23}$ que, com o lançamento do e-RMB, as autoridades também objetivam criar um sistema internacional de pagamentos alternativo ao SWIFT, dominado pelo dólar e pela influência política dos Estados Unidos, suas instituições e aliados. Na sua visão:

\begin{abstract}
Uma moeda digital soberana provê uma alternativa funcional ao sistema de compensações em dólares e atenua o impacto de quaisquer sanções ou ameaças de exclusão tanto no nível dos países quanto das empresas. Ela também pode facilitar a integração nos mercados de moedas globalmente transacionadas com um risco reduzido de perturbação politicamente motivada.
\end{abstract}

Então, afirmando que a estabilidade do renmimbi durante a crise provocada pela pandemia do Covid19 aumentou a sua demanda internacional, o jornal declarou que "os dois sistemas de pagamentos - dólar [...] e a [moeda] soberana digital da China - podem operar lado a lado ou, se necessário, sob bases mutuamente exclusivas".

Diante disso, concluímos que a criação do "renmimbi digital" não atendeu apenas ao interesse das autoridades em estabelecer o seu domínio sobre as tecnologias que servem de base ao bitcoin e às criptomoedas, asseverando o seu emprego em favor dos controles monetários e da segurança financeira do país. Ela

${ }^{22} \mathrm{PBOC}$ confirms digital currency pilot. Central Banking, 2020. Disponível em: <https://www.centralbanking.com/fintech/cbdc/7529621/pboc-confirms-digital-currency-pilot>. Acesso em: 3 de maio de 2020; CHINA starts major trial of state-run digital currency. The Guardian, 2020. Disponível em: <https://www.theguardian.com/world/2020/apr/28/china-starts-major-trial-of-state-rundigital-currency>. Acesso em: 3 de maio de 2020. Traduções livres.

${ }^{23}$ THE future of China's economic engagement. China Daily, 2020. Disponível em: <https://www.chinadaily.com.cn/a/202004/24/WS5ea28240a310a8b2411516bf.html>. Acesso em: 3 de maio de 2020. Traduções livres. 
também correspondeu aos seus anseios de escapar da hegemonia do dólar e projetar a influência monetária chinesa para o exterior, no limite, até mesmo questionando a supremacia dos Estados Unidos na atual ordem monetária internacional.

\section{Resumo e considerações finais}

Movidas pelo interesse em preservar a soberania monetária e a sua prerrogativa de continuar comandando o desenvolvimento e a expansão do poder nacional do seu país, as autoridades chinesas viram no bitcoin uma ameaça à sua segurança financeira. Por isso, reprimiram, pelos mais diversos meios e nem sempre com o sucesso esperado, o uso desse instrumento no território sob a sua jurisdição.

Porém, ao mesmo tempo, essas autoridades viram nas tecnologias que servem de base ao bitcoin uma oportunidade para ampliar os seus poderes de monitoramento e intervenção sobre as transações financeiras do país e as transações realizadas pelos seus cidadãos. Projetaram, então, a criação de uma "moeda digital soberana", sob o seu controle político.

O resultado dessa iniciativa foi o recente lançamento do e-RMB, uma representação digital do renmimbi que significa a utilização daquelas tecnologias aos interesses e objetivos do Estado chinês. Por seu intermédio, as autoridades declararam objetivar não somente maior rapidez e eficácia na execução das suas políticas internas, sejam elas voltadas para a estabilidade financeira, 0 desenvolvimento produtivo ou a vigilância da ordem social, mas também expandir a sua autonomia e influência nas relações internacionais. Ou seja, justamente ampliar a soberania monetária e a segurança financeira do seu país.

Sem dúvidas, trata-se de uma clara indicação de que, ao cabo, o advento do bitcoin tenha produzido um resultado diametralmente oposto ao pretendido pelos seus idealizadores. Assim, as tecnologias das criptomoedas, concebidas para "empoderar" os indivíduos, parecem estar prestes a permitir aos governos a ampliação dos seus poderes sobre eles. E não apenas sobre eles, pois pretende-se que o e-RMB seja uma futura alternativa aos sistemas de pagamentos dominados pelo dólar e sob a influência dos Estados Unidos. Trata-se, portanto, de um potencial instrumento de disputa pela supremacia da ordem monetária internacional.

Em suma, considerando-se o caráter de plena novidade dessa iniciativa, resta acompanharmos os seus resultados. Tendo por trás um Estado nacional poderoso como o chinês, é provável que o e-RMB obtenha sucesso em ampliar as 
capacidades internas e externas das autoridades que o controlam, o que deverá encorajar as de outros países a tomarem os seus passos como modelo.

Dessa forma, essa moeda digital representativa da soberania chinesa terá consequências teóricas e práticas transformadoras nas Relações Internacionais, na Ciência Política e na Economia Política Internacional. Porém, não podemos prevêlas.

\section{REFERÊNCIAS}

ANTONOPOULOS, Andreas M. The internet of Money, volume 1. Seattle: Merkle Bloom LLC, 2016.

ANTONOPOULOS, Andreas M. The internet of Money, volume 2. Seattle: Merkle Bloom LLC, 2017.

BANCO POPULAR DA CHINA. Transcript of Governor Zhou Xiaochuan's Exclusive Interview with Caixin Weekly. 2016. Disponível em:

<http://www.pbc.gov.cn/english/130721/3017134/index.html>. Acesso em: 8 de fev. de 2018.

BEIJING bans bitcoins, but when did it all go wrong for cryptocurrencies in China? South China Morning Post, 2018. Disponível em:

$<$ http://www.scmp.com/news/china/economy/article/2132119/beijing-bans-bitcoin-when-did-itall-go-wrong-cryptocurrencies >. Acesso em: 6 de fev. de 2018.

BITCOIN slides after China central bank launches investigation. Reuters, 2017. Disponível em: <https://www.reuters.com/article/us-markets-bitcoin-pboc/bitcoin-slides-after-chinacentral-bank-launches-investigation-idUSKBN14V10B >. Acesso em: 6 de fev. de 2018.

CHINA starts major trial of state-run digital currency. The Guardian, 2020. Disponível em: $<$ https://www.theguardian.com/world/2020/apr/28/china-starts-major-trial-of-state-run-digitalcurrency>. Acesso em: 3 de maio de 2020.

CHINA State TV: OTC Bitcoin Platforms May Violate Law. Coindesk, 2017. Disponível em: $<$ https://www.coindesk.com/china-state-tv-otc-bitcoin-platforms-may-violate-regulation/>. Acesso em: 7 de fev. de 2018.

CHINA to stamp out cryptocurrency trading completely with ban on foreign platforms. South China Morning Post, 2018. Disponível em: <http://www.scmp.com/business/bankingfinance/article/2132009/china-stamp-out-cryptocurrency-trading-completely-ban>. Acesso em: 6 de fev. de 2018.

CHINA'S central bank is developing its own digital currency, even as it bans bitcoin and private cryptos. South China Morning Post, 2017. Disponível em:

<http://www.scmp.com/business/companies/article/2118468/chinas-central-bank-studying-itsown-digital-currency-even-it>. Acesso em: 20 de fev. de 2018.

CHINA'S ICO ban: a Full Translation of Regulator Remarks. Coindesk, 2017. Disponível em: <https://www.coindesk.com/chinas-ico-ban-a-full-translation-of-regulator-remarks/>. Acesso em: 1 de dez. de 2017.

COHEN, Benjamin J. A Geografia do Dinheiro. São Paulo: Editora Unesp, 2014. 
COHEN, Benjamin J. Currency Power: Understanding Monetary Rivalry. Princeton, NJ: Princeton University Press, 2015.

DAVIES, Glyn. A History of Money from Ancient Days to the Present. Cardiff: University of Wales Press, 2002.

EICHENGREEN, Barry. Privilégio Exorbitante: a ascensão e queda do dólar. Rio de Janeiro: Campus/Elsevier, 2011.

EHA, Brian Patrick. How Money Got Free: bitcoin and the fight for the future of finance. Londres: Oneworld Publications Ltd., 2017.

FERREIRA FILHO, Valter Duarte. Economia: obstáculo epistemológico: estudo das raízes políticas e religiosas do imaginário liberal. Rio de Janeiro: EdUERJ, 2015.

GRAEBER, David. Debt: the first 5000 years. New York: Melville House Publishing, 2011.

JAPAN: The New Heart of Bitcoin. Coindesk, 2017. Disponível em:

<https://www.coindesk.com/japan-new-heart-bitcoin/>. Acesso em: 18 de mar. de 2018.

KISSINGER, Henry. Sobre a China. Rio de Janeiro: Objetiva, 2011.

KOSINSKI, Daniel. Bitcoin e Criptomoedas: a utopia da neutralidade e a realidade política do dinheiro. Rio de Janeiro: Editora UFRJ, 2020.

LI, Junru. Governing China in the New Era. Beijing: Foreign Languages Press Co. Ltd, 2018.

MEDEIROS, Carlos A. China: entre os Séculos XX e XXI. In: FIORI, José Luís (Org.). Estados e moedas no desenvolvimento das nações. Petrópolis: Vozes, 1999.

NAKAMOTO, Satoshi. Bitcoin: A Peer-to-Peer Electronic Cash System. 2009. Disponível em: < https://bitcoin.org/bitcoin.pdf>. Acesso em: 17 de out. de 2017.

ON Digital Currencies, Central Banks Should Lead. Bloomberg, 2016. Disponível em: $<$ https://www.bloombergquint.com/onweb/2016/09/01/on-digital-currencies-central-banksshould-lead>. Acesso em: 8 de fev. de 2018.

ONE chart shows how the Chinese bitcoin market collapsed in 2017. Business Insider, 2017. Disponível em: <http://markets.businessinsider.com/currencies/news/morgan-stanleychart-on-yuan-dollar-yen-euro-volumes-in-bitcoin-market-2017-12-1012338966>. Acesso em: 6 de fev. de 2018.

ONE country dominates the global bitcoin market. Business Insider, 2017. Disponível em: $<$ http://www.businessinsider.com/bitcoin-trading-china-yuan-remnibi-2017-1>. Acesso em: 6 de fev. de 2018.

PBOC Digital Currency Director Calls for Centralized State Cryptocurrency. Coindesk, 2017. Disponível em: <https://www.coindesk.com/pboc-digital-currency-director-calls-centralizedstate-cryptocurrency/>. Acesso em: 8 de fev. de 2018.

PBOC confirms digital currency pilot. Central Banking, 2020. Disponível em: $<$ https://www.centralbanking.com/fintech/cbdc/7529621/pboc-confirms-digital-currency-pilot>. Acesso em: 3 de maio de 2020

POPPER, Nathaniel. Digital Gold: The Untold Story of Bitcoin. London: Penguin Books, 2015. 
ROBERTS, J. A. G. História da China. Lisboa: Edições Texto \& Grafia, 2012.

ROUBINI, Nouriel e MIHM, Stephen. A economia das crises: Um curso-relâmpago sobre o futuro do sistema financeiro internacional. Rio de Janeiro: Intrínseca, 2010.

THE future of China's economic engagement. China Daily, 2020. Disponível em: $<$ https://www.chinadaily.com.cn/a/202004/24/WS5ea28240a310a8b2411516bf.html>. Acesso em: 3 de maio de 2020.

VIGNA, Paul e CASEY, Michael. J. Cryptocurrency: the Future of Money? London: Vintage, 2016.

VOGEL, Ezra F. Deng Xiaoping and the Transformation of China. Cambridge e London: The Belknap Press of Harvard University Press, 2011.

WHAT happened to initial coin offerings in China? South China Morning Post, 2018. Disponível em: <http://www.scmp.com/tech/china-tech/article/2132319/what-happened-initialcoin-offerings-china $>$. Acesso em: 6 de fev. de 2018.

XI, Jinping. The Governance of China II. Beijing: Foreign Languages Press Co. Ltd, 2017.

ZARATE, Juan C. Treasury's war: the unleashing of a new era of financial warfare. New York: PublicAffairs, 2013.

ZHENG, Bijian. Economic Globalization and China's Future. Beijing: Foreign Languages Press Co. Ltd, 2018.

\section{NOTAS DE AUTOR}

\section{CONTRIBUIÇÃO DE AUTORIA}

Daniel S. Kosinski - Concepção; Coleta de dados; Análise de dados; Elaboração do manuscrito; Participação ativa na discussão dos resultados; Revisão e aprovação da versão final do trabalho.

Valter Duarte Ferreira Filho - Análise de dados; Elaboração do manuscrito; Participação ativa na discussão dos resultados; Revisão e aprovação da versão final do trabalho.

\section{FINANCIAMENTO}

Não se aplica.

\section{CONSENTIMENTO DE USO DE IMAGEM}

Não se aplica.

\section{APROVAÇÃO DE COMITÊ DE ÉTICA EM PESQUISA}

Não se aplica.

\section{CONFLITO DE INTERESSES}

Não há conflitos de interesses a informar.

\section{LICENÇA DE USO}

Este artigo está licenciado sob a Licença Creative Commons CC-BY. Com essa licença você pode compartilhar, adaptar, criar para qualquer fim, desde que atribua a autoria da obra.

\section{HISTÓRICO}

Recebido em: 25-05-2020

Aprovado em: 10-07-2020 